\title{
A Análise Foucaultiana do Discurso e sua Utilização em Pesquisa Etnográfica
}

\author{
Izabel Christina Friche Passos* (D) \\ Universidade Federal de Minas Gerais, Belo Horizonte, MG, Brasil
}

\begin{abstract}
RESUMO - O artigo discute alguns conceitos fundamentais da arqueologia proposta por Michel Foucault como estratégia de análise da dimensão discursiva da realidade para, na sequência, apresentar a forma como esse modo de análise do discurso foi utilizado em uma pesquisa etnográfica concreta. Demarca-se a especificidade da análise foucaultiana do discurso em relação a outros tipos possíveis, a partir da discussão sumária dos principais resultados alcançados pela pesquisa. $\mathrm{O}$ objetivo é elucidar a pertinência do uso da $\mathrm{AD}$ em pesquisas qualitativas, especialmente a etnográfica. Deixa-se sugerida a necessidade de se abarcar na análise a dimensão genealógica das relações de poder envolvidas em toda prática discursiva.
\end{abstract}

PALAVRAS-CHAVE: discurso, arquivo, enunciado, formação discursiva, etnografia

\section{Foucault's Analysis of Discourse and their Use in Ethnographic Research}

\begin{abstract}
This study aimed to discuss basic concepts of archeology proposed by Michel Foucault as an analytical strategy of discursive dimension of reality and to show how this type of discourse analysis (DA) was used in ethnographic research. We outlined the specificity of Foucault's discourse analysis in relation to other types of discourse analysis, using for that a brief discussion of the main results achieved with the research. The goal was to understand the relevance of DA in qualitative research, particularly ethnographic research. We suggested the need to consider the genealogical dimension of power relations in every discursive practice.
\end{abstract}

KEYWORDS: discourse, file, enunciation, discursive formation, ethnography

A noção de discurso tem sido cada vez mais utilizada para definir objetos de pesquisa no campo das ciências humanas e sociais. Fala-se em analisar o discurso de profissionais, de políticos, de jovens, de mulheres, de trabalhadores etc., acrescentando-se algum adjetivo que identificaria esses sujeitos como relacionados a um determinado campo de problemas ou de práticas sociais, como por exemplo: mulheres vitimas de violência; jovens em conflito com a lei; profissionais da saúde; políticos de esquerda, trabalhadores da construção civil. Começa aí, na conceituação mesma do termo, uma diferença importante entre a perspectiva foucaultiana de análise do discurso e outras possíveis abordagens discursivas.

Para Foucault, o discurso se apresenta como um conceito antes de tudo filosófico, muito mais complexo do que a simples designação de um conjunto de frases ou de falas atribuíveis a indivíduos, cuja compilação nos permitiria caracterizar um grupo social específico relacionado a determinada função social ou situação problemática. Numa concepção empirista do discurso, cada indivíduo seria um exemplar substituível do grupo. Entender o discurso dessa forma é o que faz a proposta de análise de conteúdo que, por exemplo, segundo Bauer (2011), não passa de um tipo de survey (pesquisa de opinião) mais sofisticado. Nada mais distante da noção foucaultiana de discurso que tal empirismo metodológico.

Discurso em Foucault é uma dimensão de produção da realidade social, e não uma mera reunião de enunciados no sentido exclusivamente linguístico, de atos de fala ou de escrita. Em estreita articulação com uma maneira também própria de definir enunciado, para além de seu sentido linguístico corrente que o define como frase ou proposição,

*E-mail: izabelfrichepassos@gmail.com

- Submetido: 22/06/2016; Aceito:12/01/2018. 
o discurso para Foucault é uma prática sócio-histórica que só emerge ou se explicita mediante o exercício da análise. Como tal, o discurso não está dado imediatamente no que se diz ou se escreve; tampouco está oculto, pois, manifestandose geralmente, mas não exclusivamente, através de frases e proposições, não se resume ao conjunto dessas frases ou proposições enunciadas por alguém. Ao contrário, é o discurso que encerra o sentido e também a possibilidade de frases e proposições serem enunciadas sob certas condições espaço/temporais específicas.

$\mathrm{O}$ discurso, em Foucault, é uma produção coletiva e histórica, portanto anônima, que na maior parte do tempo trabalha em silêncio, dando sentido ao que dizemos e fazemos. Há, portanto, uma inversão do pensamento hermenêutico que põe na intencionalidade de um sujeito, seja ele individual ou coletivo, a origem do sentido. Em Foucault é o discurso, como prática discursiva histórica e anonimamente determinada, que define tanto o lugar de sujeito quanto o sentido ou sentidos possíveis dos enunciados linguísticos. O discurso é o que emerge ou se dá a ver, a partir de um trabalho de análise operada sobre material linguístico (textos e falas), mas não exclusivamente, pois pode incidir também sobre visibilidades materiais não-discursivas, como é o caso da forma arquitetural de um equipamento social, de que é exemplo o modelo do panóptico analisado por Foucault em Vigiar e Punir (1975/1998).

Certamente, ainda temos muito a aprender sobre como fazer análises de material iconográfico e sonoro. Falarei mais adiante da imanência entre práticas discursivas e nãodiscursivas, que, não se reduzindo nem se sobrepondo umas às outras, requerem métodos específicos de análise. Ficando, por enquanto, na consideração da dimensão propriamente discursiva ou linguística, diremos que o discurso não pertence a ninguém que pudesse se arvorar como detentor de sua origem ou de seu sentido, menos ainda como seu autor. As frases e os textos têm autores, não o discurso. $\mathrm{O}$ discurso se (re)produz, se dissipa e se multiplica, ou seja, em uma palavra circula, através de nossas práticas linguageiras, claro está, mas precisa ser deduzido delas, não são elas.

$\mathrm{Na}$ analítica foucaultiana do discurso, explicitada em Arqueologia do saber (1969/1987), que obedece a uma visão não-dialética da história, serão forjadas novas conceituações antropológico-filosóficas para conceitos oriundos de outros campos, especialmente da Linguística e da História, como os conceitos de enunciado-acontecimento, formação discursiva, arquivo e interdiscursividade. Elucidar o sentido dessas noções fundamentais da análise foucaultiana do discurso tem como propósito a sustentação de uma apropriação dessas noções pela pesquisa etnográfica. No entanto, tal apropriação só pode ser plenamente compreendida e empreendida à luz da evolução das pesquisas histórico-filosóficas de Foucault, o que extrapolaria muito os limites deste artigo. Fica sugerida ao leitor a indispensável consulta à obra.

$\mathrm{O}$ objetivo deste artigo é discutir a pertinência da utilização do método arqueológico de análise do discurso no trabalho de pesquisa empírica qualitativa, especialmente a etnográfica, sem nos esquecermos da necessária articulação com o método genealógico de análise das relações de poder, das práticas não-discursivas. Neste artigo, me aterei aos conceitos arqueológicos por uma razão quase didática. Em minha experiência de pesquisadora e professora, tenho constatado grande dificuldade por parte de jovens pesquisadores de compreender e usar apropriadamente as noções foucaultianas de análise do discurso, mesmo quando este é o enfoque de eleição.

Concluirei o artigo com uma tentativa de explicitar como venho trabalhando com AD, tomando como referência o trabalho realizado, com a colaboração de outros pesquisadores, no livro Loucura e sociedade (Passos, 2009a). Trata-se de uma pesquisa etnográfica, na qual trabalhamos sobre o material linguístico levantado através de entrevistas e observações participantes em duas comunidades que guardam muitas identidades históricoculturais, mas diferentes formas de se relacionarem com a loucura: as cidades mineiras de Prados e Barbacena.

\section{OS CONCEITOS ARQUEOLÓGICOS FUNDAMENTAIS PARA UMAAD FOUCAULTIANA:ARQUIVO, FORMAÇÃO DISCURSIVA, ENUNCIADO}

O objetivo é esclarecer alguns dos principais conceitos definidos por Foucault como compondo sua arqueologia do saber, sem os quais não se pode, a rigor, fazer uma $\mathrm{AD}$ de tipo foucaultiana. Ao utilizar a sigla $\mathrm{AD}$, estarei, como de praxe na literatura, deixando clara minha filiação à análise do discurso francesa, pois, além de Foucault, considero de importância fundamental outros autores desta vertente: Dominique Maingueneau, especialmente. Quanto a Michel Pêcheux, um dos fundadores da vertente francesa, mesmo mantendo interlocução com a obra, tomo distanciamento de sua observância de conceitos muito marcados pela tradição marxista, como o de ideologia, ou pela da psicanálise, como o de sujeito do inconsciente. Foucault, com a noção de formação discursiva, dispensa ambos os conceitos ou sugere grande cautela em sua utilização. $\mathrm{O}$ conceito de ideologia, por três razões principais: (1) nele estar implícita a distinção entre verdade (ciência) e encobrimento da verdade (ideologia), quando para Foucault existem, isto sim, regimes de verdade e produção de saberes; (2) remeter para a noção de sujeito, ainda que coletivo, que Foucault pretere, propondo em seu lugar modos de subjetivação; (3) manter vínculo com a visão marxista que coloca a ideologia como superestrutura numa posição derivada ou reflexa da infraestrutura econômica. Pêcheux, reconhecendo a 
paternidade da expressão formação discursiva a Foucault, irá propor conteúdo diferente, no qual ideologia será o conceito força (Gadet \& Hak, 1997). Quanto ao sujeito do inconsciente, as reservas de Foucault incidirão sobre a ideia de uma determinação subjetiva ou psíquica, quando, para ele, o sujeito existe na ordem do discurso que o submete e o pressupõe. Há também a recusa de certa essencialidade do sujeito psicanalítico, preferindo pensar a subjetividade como produção (Castro, 2009).

Acabou de sair o primeiro tomo da tradução para o espanhol de um denso curso de Gilles Deleuze sobre Foucault, ministrado na Universidade de Vincennes, no ano seguinte à morte do amigo, entre 22 de outubro e 17 de dezembro de 1985, versando sobre o saber (Deleuze, 2013). A íntegra dos cursos de Deleuze sobre Foucault (foram três no total: O saber; O poder; O desejo) estão sendo digitalizados e disponibilizados na internet (transcrições e gravações originais) pela Universidade de Purdue em parceria com a Universidade de Paris VIII ${ }^{1}$. Aconselho vivamente a leitura deste primeiro curso publicado para uma compreensão aprofundada dos conceitos arqueológicos, nada fáceis, diga-se de passagem. Embora já tratados por Deleuze no seu clássico Foucault (1986/1995), são expostos de forma muito mais didática no curso.

Retomarei a conceituação de apenas três desses conceitos: arquivo, formação discursiva e enunciado, que são os conceitos basilares e imbricados uns nos outros a partir dos quais Foucault estabelecerá, ao longo de Arqueologia do saber, os princípios ou as regras de formação dos discursos, que são: as regras de formação de objetos, de formação de conceitos, de rarefação e regularidade dos discursos, de interdiscursividade e de dispersão dos discursos. Não tratarei aqui dessas regras, detalhadamente expostas no livro de 1969.

A arqueologia foucaultiana tem uma aproximação metafórica com a ciência da qual empresta o nome; uma aproximação metafórica, mas muito importante. Remete para a materialidade dos discursos. À semelhança dos fósseis e artefatos colecionados pelo arqueólogo como traços a partir dos quais reconstrói a história dos costumes e da vida cultural de povos há muito desaparecidos, o arqueologista deverá encontrar os discursos que organizam uma dada formação histórica a partir das palavras, frases e proposições dispersas em seus arquivos.

Arquivo, conceito aparentemente mais apropriado em se tratando de pesquisa histórica, ganhará, entretanto, em Foucault um sentido muito diverso do que possui na disciplina História, uma vez que não se trata de modo algum do objeto inerte e estático, organizado pelos arquivistas, com o qual trabalham os historiadores. $\mathrm{O}$ arqueologista poderá utilizar, inclusive preferencialmente, este tipo de material para compor seu corpus de análise, mas o arquivo que lhe

1 Material acessível no seguinte endereço: http://www.cla.purdue.edu/ research/deleuze/Course\%20Transcriptions.html interessa não se esgota nesse nível de ordenação material. Heliana Conde Rodrigues (2009) nos ajuda a entender o sentido do conceito em Foucault, quando em seu texto "Sobre arquivos e tumbas: uma análise da expressão documento como monumento -“, traz densa reflexão sobre o equívoco de se pensar o arquivo como um conjunto do que se pôde ordenar, organizar e estabelecer através de uma inscrição ou fixação em documentos escritos. Arquivo, na análise foucaultiana do discurso, é o conjunto de todos os enunciados, de tudo o que se pôde dizer e, no que se disse, também elidir num determinado campo de práticas, o qual está inexoravelmente circunscrito por determinadas formações discursivas. Vamos nos manter um pouco mais no conceito de arquivo antes de vermos este outro, de formação discursiva.

Arquivo remete menos para a ideia de memória e de conservação do que para a de dispersão de traços deixados por uma prática, seja ela uma prática discursiva, isto é, os saberes constituídos num determinado momento histórico, que interessa especialmente ao arqueologista, seja ela uma prática material: artística, arquitetônica ou técnica. Neste sentido, os arquivos são formados antes pelo que se encontra disperso, emaranhado, esquecido ou transformado, e não apenas, nem prioritariamente, pelo que está organizado em textos e testemunhos canônicos, ordenados, cuidadosamente preservados ou criteriosamente classificados.

Foucault, portanto, redefiniu arquivo contra o conceito corrente de um lugar específico onde são preservadas palavras e coisas como testemunhos da e para a memória. Para ele, o arquivo mais precioso é o produzido segundo regras anônimas que comandam tanto a dispersão quanto a possibilidade, ou melhor, a necessidade e a raridade dos enunciados em uma dada formação discursiva. Nesse sentido, o arquivo é o conjunto de todos os enunciados que puderam ser expressos em palavras, imagens e sons, isto é, em alguma materialidade físico-social por uma formação histórica. Do mesmo modo, o que garimpa o filósofo arqueologista são as regras históricas que tornaram alguns enunciados dizíveis, repetíveis, memoráveis e outros tantos indizíveis, inacessíveis, ou devendo desaparecer, serem esquecidos e renegados.

O que garimpa o arqueologista são as condições de possibilidade de emergência dos enunciados de uma época ou de um contexto histórico. Formação discursiva é precisamente o conjunto das regras que permitem o aparecimento de certos enunciados e não outros. Um discurso, produzido no interior de uma formação discursiva, é, por sua vez, um conjunto mais ou menos delimitável, pois nunca pode ser completamente isolado de outros discursos com os quais faz fronteira, interpenetra ou disputa espaço. Está constituído por um número limitado de enunciados que provêm de um mesmo sistema de formação. Assim, podemos falar de discurso clínico, discurso político, discurso econômico, discurso psiquiátrico, discurso jurídico etc., como tipos de discurso que compõem a episteme moderna, 
pois seguem regras de formação características de tal episteme.

Foucault detalha em Arqueologia do saber as diferenças entre as regras de formação do discurso daquelas de uma análise formalista da linguagem (regras de estruturas sintáxicas, gramaticais e semânticas) e das regras de interpretação de texto (busca pelo significado a partir de noções como autor, livro, obra, temática - noções que Foucault dispensa ou suspende). Essas regras, como já dito, serão a raridade e regularidade dos enunciados, as regras de constituição de certos conceitos e objetos, e não outros, a dispersão e interdiscursividade dos discursos.

$\mathrm{O}$ enunciado tem existência para além do mero ato material da enunciação ou da escrita de uma frase, podendo inclusive se materializar em formas não gramaticais, como por exemplo, as palavras dispostas em coluna numa gramática latina: amo, amas, amat, que remetem para uma conjugação verbal (exemplo dado por Foucault), ou as letras escritas num papel na ordem em que se encontram distribuídas no teclado de uma máquina de escrever francesa (exemplo muito retomado por Deleuze). O enunciado, em geral materializado na forma de frase ou proposição (científica, filosófica ou de qualquer outra natureza), para adquirir o estatuto de enunciado no sentido arqueológico, precisa atender a três exigências: referir-se a objetos e a sujeitos; entrar em relação com outros enunciados; ser repetível (Castro, 2009).

O sujeito do enunciado não é nem o sujeito do ato de enunciação (aquele que diz ou escreve a frase ou proposição), nem o sujeito psicológico, transcendental ou racional (da filosofia e da lógica), que remete para a intencionalidade ou racionalidade contidas na proposição, tampouco é o sujeito da frase, que vem a ser o sujeito gramatical. O sujeito do enunciado é, melhor dizendo, uma posição de sujeito, isto é, remete para quem está sócio-historicamente autorizado a enunciá-lo. $\mathrm{O}$ enunciado remete também a um domínio de objetos que constituem um domínio de saber. Dessa forma, os enunciados não remetem a uma instância fundadora (autor, obra), mas necessariamente a outros enunciados constituídos dentro do mesmo sistema de formação e que por isso podem ser repetidos. Daí que Foucault muitas vezes utiliza a expressão prática discursiva para ressaltar que o discurso é uma prática e precisa ser atualizado e repetido para permanecer.

Edgardo Castro (2009) faz uma aproximação entre enunciados, no sentido foucaultiano, com atos ilocucionários descritos por Searle (1969/1981), na esteira da teoria dos atos de fala de Austin (1962/1990). Entendidos como propriamente atos e não meros enunciados linguísticos (atos de dizer), os atos ilocucionários, mais que dizer, fazem algo; são ações, como na frase "eu te prometo", que é um ato de promessa, e, mesmo, criam realidade, como no enunciado "eu te batizo". Para tanto, obedecem a regras constitutivas que posicionam o sujeito da enunciação em certo lugar, de tal modo que a formulação do enunciado tenha efeito de realidade. Os atos ilocutórios ou ilocucionários se comportariam em relação às regras constitutivas que lhes permitem funcionar como atos de modo semelhante aos enunciados foucaultianos em relação às normas históricas que determinam sua regularidade. Haveria certa proximidade entre a função enunciativa de Searle com as formações discursivas de Foucault, segundo Castro (2009). De fato, para Foucault, os enunciados têm valor de acontecimentos, mas, no meu entender, em um sentido histórico-filosófico muito mais fundamental que o conceito searliano, que se refere ao uso efetivo e em ato da linguagem por falantes. $\mathrm{O}$ enunciado em Foucault subjaz silenciosamente aos enunciados linguageiros.

Deleuze dirá que o enunciado é primordial na arqueologia. Considerando isso, precisamos entender o sentido de "primordial", uma vez que este conceito só alcança seu sentido radical e, assim, sua importância para o arqueologista, se compreendido juntamente com os de arquivo, discurso e formações discursivas. Precisaremos considerar igual e imediatamente as formações nãodiscursivas ou extradiscursivas (as visibilidades, na linguagem de Deleuze), as quais o primado do enunciado não apagará, mas muito ao contrário, a elas se associará. É precisamente em relação ao não-discursivo que o enunciado tem primordialidade. Esta noção do não-discursivo ganhará relevo no Foucault genealogista, que nos interessa muito de perto para nossas pesquisas etnográficas, como veremos adiante. Ainda segundo Deleuze, o primado do enunciado nunca será sinônimo de um reducionismo à dimensão discursiva. "Do princípio ao fim da obra de Foucault, as visibilidades permanecerão irredutíveis aos enunciados, ainda mais irredutíveis porque parecem formar uma paixão em comparação com a ação dos enunciados", dirá Deleuze (1995, p. 59).

Nos livros da fase arqueológica, "o primado do enunciado sobre as formas do ver e do perceber" é, principalmente, para Deleuze (2013), "uma reação contra a fenomenologia". Como não se cansará de afirmar, no seu curso sobre o saber: “(...) não há nada sob o saber ou antes do saber”. Nada como uma experiência originária, como quer a fenomenologia. Isso implica que "saber", para Foucault, "terá um sentido completamente diferente de "conhecer" (p.41). O saber não é conhecimento e não se trata da relação de um objeto para um sujeito; um objeto pré-existente ou que exista no exterior do pensamento e que o pensamento finalmente apreenderia. Trata-se sempre de objetos discursivos, isto é, existentes dentro e segundo uma ordem discursiva determinada historicamente. $\mathrm{O}$ enunciado não remete a um objeto exterior a ele ou ao discurso, mas, muito ao contrário, remete a um domínio de objetos que são interiores ao próprio discurso e são formados em seu interior. Tampouco se trata de uma atitude idealista ou ingênua, segundo a qual o discursivo por si só pudesse dar conta da complexidade da realidade. O enunciado é um primado, exatamente porque incide sobre algo que lhe é irredutível: as visibilidades, mas operando 
a partir de sua própria formação. Foucault é, neste sentido, a meu ver, um pragmático radical. Aqui, estamos no cerne de uma difícil discussão filosófica que não temos como aprofundar; novamente, remeto o leitor para o curso e para o livro de Deleuze.

De outro lado, agora contra a linguística tradicional, o enunciado não é definido como frase, proposição, ato de fala ou performance verbal, mas como um acontecimento histórico que não está dado a priori; ao contrário, precisa da análise para se dar a ver. Vai mais além de uma mera manifestação expressiva possibilitada pelo uso da linguagem. Insistindo, o enunciado é mais que um simples conjunto de marcas materiais, pois se refere a um domínio de objetos, implica posições de sujeito, relaciona-se com outros enunciados e encerra a possibilidade de sua repetição. O enunciado é produzido por condições históricas que demandam análise para sua elucidação. Não é aparente ou visível, mas tampouco está escondido pelos atos de linguagem, pois é através destes atos que alcançamos o enunciado e que ele se exerce como tal. Existe através e por meio dos atos de linguagem, de frases e proposições, mas não são essas frases e proposições. A análise deve alcançar as formações discursivas, que são as condições de produção de frases e proposições enquanto enunciados que constituem objetos e definem posições de sujeito.

Portanto, o trabalho do analista do discurso consiste em elucidar as condições de possibilidade do que se diz e do que se faz dizer numa determinada época ou formação histórica, bem como do que se vê e do que se dá a ver nessa época. Assim, por exemplo, a loucura enunciada como desrazão se dá a ver no hospital geral, que reúne os desajustados sociais de toda ordem: loucos, mendigos, prostitutas e vagabundos. A loucura seria a forma acabada da desrazão para a época clássica, séculos XVII e XVIII. Sofrerá uma torção fundamental na época moderna, a partir do final do século XVIII, quando sua enunciação não se dará mais por relação à razão, mas por relação à saúde: passará a ser enunciada como doença e sua visibilidade será o hospital psiquiátrico, a partir da constituição de um novo saber especializado: a psiquiatria.

Deleuze (1992) propõe rachar as coisas (as visibilidades) e as palavras (frases e proposições) para extrairmos delas os enunciados. Entretanto, entre visibilidades (que não são dadas apenas pela visão, mas por todos os sentidos) e discursos, dos quais os enunciados são como átomos, não há nem correspondência ou conformidade, nem total independência. "Há diferença entre falar e ver, entre o visível e o enunciável", mas há também constante remissão de um a outro. Cito mais longamente Deleuze (1986/1995):

Enquanto nos atermos às coisas e às palavras, podemos acreditar que falamos do que vemos, que vemos aquilo de que falamos e de que os dois se encadeiam: é que permanecemos num exercício empírico. Mas assim que abrimos as palavras e as coisas, assim que descobrimos os enunciados e as visibilidades, a fala e a visão se alçam a um exercício superior, a priori, de forma a cada uma atingir seu próprio limite que a separa da outra, um visível que tudo o que pode é ser visto, um enunciado que tudo que pode é ser falado. (p.74)

Deleuze, citando o próprio Foucault, irá pinçar algumas frases esclarecedoras:

(...) por mais que se diga o que se vê, o que se vê não se aloja jamais no que se diz, e por mais que se faça ver o que se está dizendo por imagens, metáforas, comparações, o lugar onde estas resplandecem não é aquele que os olhos descortinam, mas o que as sucessões das sintaxes definem..." “(...) de outro lado, é preciso admitir, entre a figura e o texto, toda uma série de entrecruzamentos, ou antes ataques lançados de um ao outro, flechas dirigidas contra o alvo adversário, operações de solapamento e de destruição... uma batalha" "(...) invasão do discurso na forma das coisas. (Frases de Foucault do Arqueologia do saber citadas por Deleuze, 1995, p.75).

Esse modo de nos posicionarmos diante da realidade implica permanentes jogos de resistência entre discursos e práticas, entre práticas discursivas e não-discursivas. Entre estas há mais lutas e tensões que complementaridade de parte a parte, assim como há disputas entre os próprios discursos. Por exemplo, num caso de crime que envolva a suspeita de um distúrbio mental, pode haver complementaridade ou disputa entre a formação discursiva da medicina e a da justiça ou entre discursos medicalizantes e discursos psicologizantes. Daí a possibilidade de multiplicação, germinação e proliferação dos enunciados na tessitura da história.

Mas há, rigorosamente falando, uma limitação dos discursos nas formações históricas. Deleuze (2013), novamente, nos esclarece, citando livremente Foucault:

Toda formação histórica vê tudo o que é capaz de ver, vê tudo o que pode ver, e diz tudo o que pode dizer. Uma formação histórica se definirá por suas evidências, isto é, por seu regime de luz. E pelo quê mais? Por suas discursividades. (...) Evidências e discursividades. (p.24)

Deleuze, voluntária ou involuntariamente, nos tranquiliza: não precisamos nos debater tanto nas ciências humanas contra a noção de evidência, cada vez mais cara ao saber positivo biomédico dos dias atuais. Simplesmente, devemos lembrar a seus ardorosos defensores que é precisamente de evidências que se trata, ou seja, daquilo que podemos ver ou somos capazes de ver com a visão com a qual nos damos a ver e a dizer o que vemos ${ }^{2}$.

2 A propósito, uma coletânea de textos antropológicos, fruto de extenso debate realizado em Tarragona Catalunha/ES, em 2010, ilustra bem o debate sobre os equívocos que cercam a "medicina baseada em evidências", como ficou traduzida a expressão evidence-based medicine. Os textos trazem propostas alternativas nomeadas como "medicina baseada em narrativas", propondo uma reflexão sobre as narrativas da evidência (do poder biomédico e de suas expressões discursivas e práticas) e a evidência das narrativas (das vozes do sofrimento). (Matínez-Hernáez, Masana \& Digiacomo, 2013). 
Não faz sentido pensar que a Idade clássica teve uma incapacidade para ver/dizer a doença mental devido a uma precariedade do saber da época em relação a um suposto maior esclarecimento de nossa formação discursiva moderna. Cada época vê/diz aquilo que se dá a ver/a dizer. O trabalho do analista consiste em tornar visível e dizível as regras históricas que permitem ver o que se vê e falar o que se fala. Ou seja, o trabalho do analista é pensar o impensado de um pensamento, ver o invisível de uma visibilidade, dizer o indizível de uma discursividade. Trabalho sempre tateante e nunca acabado, pois implica num permanente movimento de deslocamento, especialmente quando o que se está analisando é parte de nosso próprio presente.
Deleuze considera Foucault uma espécie de neokantiano, não porque cresse, como Kant, na limitação de nossa razão em relação ao conhecimento absoluto, tampouco porque pensasse que o real escapa sempre à razão, mas porque nossa discursividade está submetida a regras históricas na sua produção. Elucidar estas regras seria o trabalho do arqueologista. Desta forma, Foucault também se distancia da posição do hermeneuta contemporâneo, para quem haveria uma proliferação, uma multiplicação incessante de interpretações possíveis. Há, isto sim, uma proliferação de objetos na longa história, mas sempre dentro de uma raridade discursiva que é preciso elucidar.

\section{ETNOGRAFIA E AD FOUCAULTIANA: PERTINÊNCIAS}

Neste tópico, gostaria de abordar o segundo objetivo do artigo: discutir a pertinência da arqueologia e da genealogia foucaultianas para a pesquisa empírica social qualitativa, tentando esclarecer para o leitor a forma como venho utilizando a análise do discurso em estudos de caso e em pesquisas etnográficas. $\mathrm{O}$ trabalho com a $\mathrm{AD}$ foucaultiana que trago para ilustrar a discussão foi concluído em 2007 com a colaboração de uma grande equipe de pesquisa (Passos, 2009a). A partir desse trabalho, tentarei refletir sobre os procedimentos adotados e os achados de pesquisa que considero igualmente tributários dos métodos arqueológico e genealógico de Foucault. Dado o espaço exíguo de um artigo, não tratarei do segundo ${ }^{3}$.

Embora os corpora de Foucault nem sempre fossem muito claramente delimitados, algumas vezes sequer explicitados, o primeiro passo para a realização de uma análise do discurso é a delimitação de um corpus ou corpora. Uma análise do discurso só pode ser iniciada a partir da definição ou delimitação de um corpus pelo analista sobre o qual incidirá a análise. O corpus vem a ser um conjunto delimitado de objetos empíricos (textos, imagens e registros sonoros) que tenham uma mesma natureza material (uma pesquisa pode ter mais de um corpus, mas não se misturam objetos de naturezas diferentes num mesmo corpus), selecionados segundo critérios definidos a partir do objetivo ou problema de pesquisa. Se for bem delimitado, o analista terá boas chances de, no processo de análise, encontrar os enunciados que configuram a formação discursiva em questão. O corpus pode ser pré-existente ou coconstruído pelo analista, como é o caso de textos oriundos de pesquisa empírica qualitativa, geralmente, neste caso, transcrições literais de entrevistas feitas pelo próprio pesquisador. Discutirei a seguir os desdobramentos do segundo tipo de corpus, característico de pesquisas etnográficas, ao tratar

3 A literatura sobre a genealogia foucaultiana é vastíssima, tratei dela em outra ocasião (Passos, 2009b). de possíveis aproximações entre a $\mathrm{AD}$ foucaultiana e a etnografia.

Loucura e sociedade: Discursos, práticas e significações sociais, como veio a se chamar o livro que narra a referida pesquisa na qual baseio esta discussão, nasceu de um enunciado circulante que indicava a problematização de uma prática social. Trabalhando como professora na Universidade Federal de São João del Rei, distante $12 \mathrm{~km} \mathrm{da}$ cidade de Prados e $50 \mathrm{~km}$ de Barbacena, que ganhou fama nacional de "cidade dos loucos", a partir de sua pesada e violenta história manicomial (Firmino, 1982), chamou-me a atenção ouvir por mais de uma vez a frase: "Prados não interna seus loucos". É especialmente intrigante o fato de esta pequena cidade de pouco mais de 12 mil habitantes ser também vizinha de Barbacena, cidade que chegou a abrigar mais de uma dezena de clínicas psiquiátricas privadas, além da primeira e maior colônia psiquiátrica pública do estado de Minas Gerais, hoje Centro Hospitalar Psiquiátrico de Barbacena. Desde sua inauguração em 1903, este hospital psiquiátrico não cessou de multiplicar sua população de internos e chegou a ter mais de 3 mil pessoas, vindas de todos os cantos do país e "abrigadas" em condições absolutamente degradantes, até que, na década de 1990, o processo de reforma psiquiátrica começou a reverter essa história. O número de instituições psiquiátricas na cidade não é sem importância se considerarmos que Barbacena nunca atingiu mais de cem mil habitantes. A cidade viveu o século XX sob forte impacto desta instituição social e de sua progressiva degradação.

Talvez exatamente por compartilharem o mesmo contexto sócio-histórico, as pessoas naturais de Prados ou a ela afeiçoadas faziam e fazem questão de demarcar sua diferença em relação a Barbacena. A pesquisa procurou identificar os discursos circulantes entre os moradores das duas cidades a propósito da loucura. Interessava-nos elucidar os discursos característicos das duas comunidades discursivas e não apenas, nem prioritariamente, o discurso médico-psiquiátrico, pois queríamos exatamente ver 
a penetração ou não, a convivência e os conflitos com este discurso hegemônico, socialmente legitimado pelas sociedades ocidentais modernas para tratar da loucura.

A pesquisa se beneficiou de uma combinação de diferentes estratégias metodológicas: imersão nos campos de pesquisa, através da realização continuada de estágios de psicologia em instituições assistenciais das duas cidades, o que propiciou uma compreensão enriquecida pela construção de vínculos psicossociais e afetivos com os sujeitos de pesquisa; pesquisa histórica sobre o grande manicômio de Barbacena, desenvolvida paralelamente por um dos membros da equipe; construção de relatos de histórias de vida de "loucos" das cidades. Neste artigo, privilegio a análise do discurso que se constituiu como o núcleo principal da pesquisa.

Seguindo uma orientação de Howard Becker (1999), realizamos primeiro o estudo em Prados e, após finalizado, iniciamos o de Barbacena, de modo a não deixarmos que um contaminasse o outro e garantíssemos uma imersão o mais completa possível dos pesquisadores em cada uma das comunidades discursivas estudadas. A composição da equipe de pesquisadores foi quase totalmente alterada no segundo estudo de caso, permanecendo apenas a coordenadora da pesquisa e a consultora como o elo entre os dois estudos.

A imersão etnográfica e o envolvimento na equipe de pesquisa de moradoras de ambas as cidades aportou contribuições importantes para a análise dos discursos. O acesso direto às realidades locais nos permitiu compreender os ritos sociais, os modos cotidianos de funcionamento das instituições relacionadas ao tema da pesquisa, as relações sociais e de classe, os valores culturais e religiosos, os emblemas locais etc. A observação participante, especialmente em sua fase exploratória, nos permitiu mapear os atores sociais mais significativos em cada comunidade em relação ao problema de pesquisa. Permitiu-nos também identificar os chamados informantes-chave, pessoas fundamentais a entrevistar. Tínhamos um critério geral, mas flexível, de escolha dos entrevistados: que fossem pessoas significativas para a vida das cidades ou que tivessem com elas uma relação de forte pertencimento, não exclusivamente em termos de poder institucional, mas de valor social, isto é, que fosse uma pessoa comunitariamente reconhecida ou tivesse coisas significativas a nos contar em relação à experiência da loucura relacionada à história da cidade. Também nos demos conta no desenrolar do trabalho, especialmente no caso de Prados, que era muito interessante entrevistar pessoas que, ao contrário, tivessem com a cidade mera relação de trabalho no campo da saúde, sem grande envolvimento pessoal. Os entrevistados foram escolhidos pelo processo de bola de neve (um entrevistado sugerindo outros) e limitados pelo critério de saturação das entrevistas em relação ao problema pesquisado.

Poderiam, então, ser entrevistados, como foram, uma dona-de-casa, um juiz, um médico, um contador de "causos", um jornalista, um líder comunitário. De modo complementar, pesquisamos a história das cidades através de seus próprios registros locais (memorialísticas publicadas, depoimentos escritos, gravações de conversas, textos ou material audiovisual produzidos por outras pesquisas, artigos jornalísticos e reportagens). Todas as entrevistas realizadas foram gravadas e minuciosamente transcritas, constituindo esse conjunto de textos o nosso corpus principal, isto é, o principal material sobre o qual se deu a análise do discurso. Essa análise, entretanto, era sempre cotejada com a leitura das mencionadas fontes documentais primárias e com as nossas anotações dos diários de campo.

À diferença da AD realizada sobre textos de arquivos, pré-existentes à pesquisa, o nosso corpus tinha uma característica própria aos corpora de pesquisa qualitativa: ser coproduzido pelos pesquisadores, o que demanda, a meu ver, necessariamente, a realização de uma análise da implicação (Altoé, 2004; Monceau, 2008). Essa talvez seja a principal dimensão que a pesquisa qualitativa acrescenta à análise do discurso, a saber: a análise da implicação dos pesquisadores e pesquisados. Segundo Monceau (2008), podemos entender a implicação como a relação que o indivíduo desenvolve com a instituição, tomada como conceito sociológico complexo. Em nosso caso, com a instituição universitária e científica, em um nível mais amplo, mas também com a própria pesquisa, em um nível mais primário: com o problema de pesquisa, os sujeitos pesquisados, as teorias escolhidas, as concepções privilegiadas. Essa discussão foi muito importante também porque estávamos trabalhando com um tema tabu para nossa sociedade, que é a loucura. Assim, a leitura do trabalho da etnóloga Jeanne Favret-Saada (1981) sobre bruxaria, sugerida pela consultora da pesquisa, foi particularmente fecunda.

A implicação existe mesmo que o indivíduo não a perceba ou tente tomar distância da instituição, e sua análise só pode ser feita de modo coletivo, pelos envolvidos no processo. Tivemos a oportunidade de expandir essa análise para além do grupo restrito de pesquisa num seminário de devolução dos resultados que fizemos em Barbacena, durante o III Festival da Loucura, evento desencadeado pelo atual contexto da Reforma psiquiátrica e que vinha sendo realizado na cidade com certa regularidade. Em Prados, ao contrário, toda tentativa nossa de fazer a devolução caiu no vazio. Isso é compreensível, pois, dentre outras razões, no contexto de Prados, a loucura não é exatamente problematizada e está muito mais incorporada à vida cotidiana.

Os resultados de pesquisas qualitativas, assim como os de análises do discurso, não são evidências reproduzíveis por outro pesquisador qualquer. São aproximações compreensivas, nunca exaustivas ou explicativas, sobre certo recorte da realidade construído pelo pesquisador. Em nossas análises, encontramos alguns discursos que nos pareceram fundamentais nas formações discursivas sobre a loucura dominantes em cada cidade. Outros pesquisadores poderiam ressaltar outros discursos e enunciados. 
Falamos da contribuição da pesquisa etnográfica para a AD. Por sua vez, o que o procedimento de $A D$ acrescenta à descrição etnográfica densa vem a ser a atenção para a interdiscursividade, para a concorrência entre os discursos que disputam os sentidos e constroem os objetos e as estratégias discursivas numa dada comunidade socio-historicamente delimitada. Assim, a AD nos ajuda a evitar uma visão unificadora e totalizante da realidade social, marcada, ao mesmo tempo, por uma pluralidade de significados, mas também por uma raridade de enunciados que se entrelaçam na produção de sentidos. Tal raridade está, evidentemente, relacionada com a formação social e histórica da comunidade em questão, mas a própria comunidade não é algo cabalmente identificável ou delimitável. Utilizamos este conceito também num sentido aproximativo, pois uma cidade, além de se constituir como unidade territorial, geográfica, política e social complexa, é uma unidade representacional formada por uma pluralidade discursiva, muitas vezes contraditória.

Na comunidade de Prados, encontramos os seguintes tipos de discurso em relação à loucura: o discurso leigo ou dos moradores da cidade, o discurso dos profissionais da saúde, o discurso jurídico e o discurso narrativo. Já em Barbacena, pudemos identificar três tipos de discursos dominantes: o discurso especialístico, o discurso leigo e o discurso jornalístico. Apesar das aparentes semelhanças nas nomeações dos discursos, são discursos com conteúdo muito diferenciado, segundo se trate de uma ou outra comunidade discursiva. Não tenho como retomar aqui a discussão de cada um deles, presente no livro; apresentarei apenas um resumo muito geral.

No caso de Prados, encontramos uma diferença importante entre os discursos de moradores da cidade e o de profissionais "de fora" da cidade que lá realizavam algum tipo de atividade, especialmente os vinculados à área da saúde. Portanto, no discurso dos profissionais da saúde era necessário discriminar o discurso circulante entre os profissionais moradores ou naturais da cidade, sensíveis às suas tradições, e aquele circulante entre "os de fora". O discurso jurídico foi identificado como relevante por uma questão contingente, mas que, após análise, veio a reforçar a identificação de uma tensão entre o discurso leigo, dos moradores, e o discurso dos profissionais "de fora". Chegou a nós, por vias indiretas, a informação de que o número de moradores de Prados enviados para internação psiquiátrica em Barbacena havia aumentado muito naqueles últimos anos. Após investigar o discurso da Justiça, descobrimos que não só aumentaram os pedidos de internação psiquiátrica para os pradenses, como subiu o número de interdições judiciais de modo exponencial a partir dos dois anos que antecederam o início da pesquisa. O juiz responsável por tais encaminhamentos e interdições atuava na cidade há muito pouco tempo, e, estando também pouco familiarizado com as diretrizes da reforma psiquiátrica, usava do expediente da interdição por transtornos mentais para facilitar às famílias muito pobres conseguir um benefício previdenciário.

Quanto ao discurso narrativo, intrinsecamente relacionado ao discurso leigo ou dos moradores, nos pareceu ser uma prática discursiva particularmente importante a se destacar naquela comunidade discursiva, associada que está à prática de contação de "causos", muito presente na cultura local. Preferimos, então, tratar os discursos de Prados aos pares, isto é, o discurso dos moradores juntamente com o discurso narrativo, no qual emerge o mito da cidade acolhedora, que não interna seus loucos; o discurso dos profissionais da saúde, no qual se diferenciavam o discurso dos profissionais moradores da cidade e aquele dos profissionais não moradores, juntamente com o discurso jurídico. Em linhas muito gerais, concluímos que em Prados predomina uma forte tradição católica, embalada na ideia de caridade e filantropia que compete com o lugar da assistência médico-formal de base científica. Os chamados "loucos de rua", principalmente, inserem-se numa rede de assistência comunitária na qual os próprios moradores se incumbem de seu cuidado e proteção. Os diversos e famosos "causos" dos loucos de Prados, folclórica e ritualisticamente lembrados, nos levaram a catalogá-los no quarto tipo de discurso, o narrativo, que preserva certa identidade e fascínio do pradense com a loucura. Os profissionais de fora viam essa tradição folclórico-religiosa de forma negativa, como dificultando o seu trabalho.

$\mathrm{Na}$ tipificação dos discursos em Barbacena, como especialístico, leigo e jornalístico, identificados não apenas através das falas dos entrevistados, mas também nos documentos pesquisados, consideramos alguns aspectos. Qualificamos como especialísticos os enunciados encontrados, principalmente, mas não exclusivamente, nas falas de profissionais e trabalhadores da área da saúde que remetiam para uma enunciação identificada ao saber especializado sobre o tema da loucura, seja por sua relação com a práxis psiquiátrica ou "psi", de um modo geral, seja pelo diálogo que estabelecia com o atual processo de reforma psiquiátrica. Embora sendo um neologismo, o termo especialístico foi preferido a especializado, pois não se trata apenas, nem prioritariamente, da dimensão do conteúdo do enunciado ser ou não pertinente ou efetivamente cabível no arcabouço de um saber especializado "psi". Trata-se, antes, de uma enunciação recorrente nas entrevistas que simplesmente remete o saber sobre a loucura para o lugar social autorizado a falar dela, que é o do especialista. Alguns entrevistados, mesmo tendo trabalhado no hospital, se diziam não qualificados para falar do assunto por não serem especialistas. Quando se tratava de um leigo, a esquiva de falar era muito mais ostensiva. A questão que se colocava era: a esquiva em falar do assunto era devida ao tabu gerado pela história mal-afamada "de cidade dos loucos" ou era a própria existência e grande penetração do saber psiquiátrico na cidade, à parte todas as mazelas de sua história, que teria gerado essa esquiva? 
Quanto ao discurso leigo, qualificamos dentro dele os enunciados que remetiam para uma relação pessoal do entrevistado com o problema pesquisado, seja por sua condição de morador ou de pessoa natural da cidade, seja por se apresentar como testemunha de sua história manicomial. Assim, o discurso pode ser enunciado também por um profissional da saúde, não sendo exclusivo de pessoas leigas, no sentido estrito do termo, isto é, não formadas academicamente em um dos saberes especializados que compõem o campo da saúde mental. Por fim, por discurso jornalístico queremos nos referir aos enunciados que ganharam uma dimensão pública, voltados para tornar pública a questão manicomial na cidade e/ou veiculados através dos meios de comunicação, bem como, naturalmente, às percepções de pessoas atuantes no campo do jornalismo e do documentário.

Apesar da enorme importância do poder judiciário Barbacena abriga o primeiro e único manicômio judiciário do estado -, malgrado os muitos esforços da equipe no sentido de acessá-lo, não conseguimos explorar o discurso da Justiça em Barbacena, junto às instituições e aos atores ligados a ela, como fizemos em Prados. Longas negociações com o poder judiciário estadual para obtenção das autorizações foram infrutíferas.

Um tipo de discurso nos foi particularmente impossível de isolar dos demais para um tratamento específico: o discurso político. A dimensão do político está absolutamente imbricada em todos os discursos em Barbacena, especialmente no discurso médico, autorizando-nos a falar de um atravessamento do político em todas as dimensões da vida dessa comunidade discursiva. Um capítulo do livro foi inteiramente dedicado a tratar da questão. Poderíamos dizer que estávamos diante de um verdadeiro dispositivo médicopolítico ${ }^{4} \mathrm{em}$ torno da loucura, que, embora característico das sociedades modernas, em Barbacena atingiu uma penetração abarcante da vida social. Segundo Foucault (1972/1995a; 2003), um tal dispositivo pôde-se constituir historicamente a partir da subsunção da loucura ao saber/poder psiquiátrico, como doença mental, daí a desqualificação de todo e qualquer saber estranho ou externo a ele.

Essa divisão em tipos de discurso não significa que cada informante seja representante exclusivo de algum deles, nem que cada um dos tipos esteja estritamente vinculado a

\footnotetext{
$4 \mathrm{O}$ conceito de dispositivo surge para Foucault em sua fase genealógica e vai além do conceito de formação discursiva, sendo compreendido como "um conjunto heterogêneo que engloba discursos, instituições, organizações arquitetônicas, decisões regulamentares, leis, medidas administrativas, enunciados científicos, proposições filosóficas, morais, filantrópicas. Em suma o dito e o não dito são os elementos do dispositivo. O dispositivo é a rede que se pode estabelecer entre estes elementos." (Foucault, 1995b, p.244). Portanto, engloba as dimensões discursiva e extra-discursiva da realidade.
}

profissões específicas ou à inserção social dos entrevistados. Uma mesma pessoa pode ser enunciadora de mais de um tipo de discurso, sem que isto signifique necessariamente uma contradição. Como nos ensina a Análise do Discurso (Charaudeau \& Maingueneau, 2004), o enunciador não se confunde com o sujeito do enunciado, sendo este produzido pelo próprio discurso que se enuncia como um lugar social que escapa à vontade consciente do enunciador ou a uma determinação absoluta do indivíduo que o enuncia. Uma característica importante a ser destacada com relação ao grupo de informantes é que a maioria absoluta foi constituída por moradores e/ou nascidos nas duas cidades.

É preciso ter em mente que tal tipificação dos discursos não corresponde a entidades pré-existentes nas realidades estudadas. Tampouco os discursos são passíveis de uma delimitação precisa de fronteiras, uma vez que estão todos imbricados na produção das formações discursivas. No contexto de Prados, encontram-se espontaneamente orientando as práticas, ao passo que em Barbacena achamse muito mais circunscritas pelas instituições sociais que as autorizam, tanto pelas instituições que se apropriaram do direito de falar da loucura (psiquiatria e justiça, especialmente) quanto pelas que abdicaram de exercer poder sobre esta (instituições políticas, religiosas, ligadas à cultura popular etc.). As tipologias sugeridas são, na verdade, um recurso analítico criado pelos próprios pesquisadores para se compreender a multiplicidade de sentidos que disputam o imaginário coletivo daquelas populações. Como tal, de modo algum a tipificação esgota as possibilidades de análise.

$\mathrm{Na}$ pesquisa, concluímos, por muitos aspectos, que Prados apresenta e tenta manter o que poderíamos chamar de "contrassignificações" em relação à significação hegemônica sobre a loucura como doença ou transtorno mental. São significações contra-hegemônicas precisamente por compartilharem o mesmo tempo histórico de Barbacena, mas mantendo em suas práticas discursivas elementos de um tempo arcaico e de um modo de vida menos marcado pelos saberes científicos modernos. Lá predomina uma visão que poderíamos chamar de barroca, ao modo como Foucault chamou de trágica e irônica a visão da loucura no Renascimento, que, à semelhança do que ocorre em Prados, a tomava como algo não desprezível e muito menos apartável da vida cotidiana ${ }^{5}$.

5 O barroco é o estilo artístico dominante no período colonial brasileiro. Introduzido no país principalmente pelos jesuítas no século XVII, deixou profundas marcas na cultura popular do interior de Minas Gerais. É considerado um desdobramento do Renascimento, com interesse pelos mesmos temas e valorização da Antiguidade Clássica, mas sendo um estilo narrativo com maior dinamismo, fortes contrastes, dramaticidade, exuberância e realismo. No Brasil está intimamente ligado à arte sacra. Prados é fecunda em festividades religiosas originárias dessa tradição e sedia todos os anos importante festival de música barroca organizado pela Universidade de São Paulo. 


\section{CONSIDERAÇÕES FINAIS}

Os modos de se fazer análise do discurso são quase tão numerosos quantos são os analistas do discurso. Fala-se em pelo menos 57 variedades (Gill, 2011), dentre elas, análises linguísticas críticas, análises semióticas, conversacionais, interacionistas, retóricas e construtivistas. Pessoalmente, faço um uso muito livre da visada histórica foucaultiana sobre o discurso como prática social. Não tomo a arqueologia nem a genealogia como metodologias em sentido estrito (Ferreira Neto, 2015), mesmo porque considero-as mais como estratégias de problematização e de tensionamento do pensamento do que como caminhos metódicos sistemáticos. No máximo, poderia dizer que me inspiro na produção do filósofo e a utilizo. Tampouco parto de, nem chego a, uma análise linguística propriamente dita. Não me ocupo especialmente em identificar marcadores conversacionais, como adjetivos, interjeições, advérbios, modos verbais e nem performatividade, tipos de trocas linguísticas etc. Nas muitas leituras e releituras que faço dos corporas coproduzidos por nós, pesquisadores, uso basicamente o método da atenção flutuante, aprendido com a psicanálise. Deixo-me ser conduzida pela associação livre de ideias e pelos efeitos de sentido que certas frases, palavras, entonações, omissões, reticências das falas dos entrevistados e das intervenções dos pesquisadores produzem em minha escuta. Na escuta do que está sendo dito e silenciado e em como está sendo dito, persigo os enunciados. Em geral, o sentido, que se configura para mim em um novo enunciado, emerge de uma vez e em bloco e assim vou persegui-lo para ver se ele se confirma realmente no material produzido pela pesquisa, seja nas transcrições minuciosas das entrevistas, seja em outras fontes levantadas (anotações de diário de campo e fontes documentais primárias). São os enunciados emergentes - como, por exemplo, o mencionado acima de uma autodesautorização do discurso leigo em Barbacena -, que me permitem identificar os discursos e a interdiscursividade presentes numa determinada formação discursiva. Não é o conteúdo dos textos, das frases e das palavras que me interessam em si ou por si mesmos como elementos linguísticos, mas os efeitos de sentido que produzem no contexto de suas formulações e enunciações. Diferentemente de uma análise de conteúdo, que procura no material dos textos de entrevistas temas e subtemas que definam categorias gerais de análise, entendidas como opiniões ou representações sociais generalizáveis, a AD etnográfica está interessada na explicitação de enunciados raros e fundamentais para certa formação discursiva. A busca é pela compreensão da singularidade histórica e cultural de tal ou qual formação discursiva não evidente, geralmente. Interessa a elucidação do lugar de sujeitos que determina e das condições sóciohistóricas de sua produção. Portanto, os enunciados não são entendidos como meras opiniões ou representações sociais generalizáveis. São, isto sim, a condição de possibilidade de constituição de objetos, percepções e conceitos, de modos de relação social e de significações sociais de base. Faz toda a diferença quem os enuncia e o contexto de sua enunciação. Uma análise do discurso nesses termos, embora submetida a contingências do momento de sua produção, tem a pretensão de ir mais além do representacional para apreender as origens genealógicas das relações de saber/ poder que estão presentes como condição de possibilidade de uma dada formação discursiva, que é sempre histórica, temporal. Certamente, cada tipo de análise tem seus alcances e limites, sua pertinência. É importante conhecê-los para não se exigir da análise o que ela não pode dar ou, ao contrário, supor estar fazendo um tipo de análise que de fato não se está. São cuidados importantes, num momento em que discurso se tornou um conceito passe-partout.

\section{REFERÊNCIAS}

Altoé, S. (Ed.). (2004). René Lourau. Analista institucional em tempo integral. São Paulo: Hucitec.

Austin, J. L. (1990). Quando dizer é fazer: Palavras e ação (D. M. De Souza Filho, trans.). Porto Alegre: Artmed. (Trabalho original publicado em 1962)

Bauer, M.W. (2011). Análise de conteúdo clássica: Uma revisão. In M. Bauer \& G. Gaskell (Eds.), Pesquisa qualitativa com texto, imagem e som. Um manual prático (P. A. Guareschi, trans., $9^{\mathrm{a}}$ ed., pp. 189-217). Petrópolis: Vozes. (Trabalho original publicado em 2000)

Becker, H. S. (1999). Métodos de Pesquisa em Ciências Sociais (M. Estevão \& R. Aguiar, trans.). São Paulo: Hucitec. (Trabalho original publicado em 1992)

Castro, E. (2009). Vocabulário de Foucault. Um percurso pelos seus temas, conceitos e autores (I. M. Xavier, trans.). Belo Horizonte: Autêntica. (Trabalho original publicado em 2004)
Charaudeau, P., \& Maingueneau, D. (2004). Dicionário de análise do discurso (F. Komesu, trans.). São Paulo: Contexto. (Trabalho original publicado em 2004)

Deleuze, G. (1995). Foucault (C. S. A. Martins \& R.J. Ribeiro, trans.). São Paulo: Brasiliense. (Trabalho original publicado em 1986)

Deleuze, G. (1992). Conversações (P. P. Pelbart, trans.). Rio de Janeiro: Editora 34. (Trabalho original publicado em 1990)

Deleuze, G. (2013). El saber - Curso sobre Foucault (P. Ires \& S. Puente, trans., tomo 1). Buenos Aires: Editorial Cactus.

Favret-Saada, J. (1981). Les mots, la mort, les sorts: Enquête sur la sorcellerie dans le bocage. Paris: Gallimard.

Ferreira Neto, J. L. (2015). Pesquisa e metodologia em Foucault. Psicologia: Teoria e Pesquisa, 31(3), 411-420. http://dx.doi. org/10.1590/0102-377220150321914100420

Firmino, H. (1982). Nos porões da loucura. Belo Horizonte: CODECRI. 
Foucault, M. (1987). A arqueologia do saber (L. F. B. Neves, trans.). Rio de Janeiro: Forenze-universitária. (Trabalho original publicado em 1969)

Foucault, M. (1998). Vigiar e punir: Nascimento da prisão (R. Ramalhete, trans.). Petrópolis: Vozes. (Trabalho original publicado em 1975)

Foucault, M. (1995a). História da loucura (J. T. C. Neto, trans.). São Paulo: Perspectiva. (Trabalho original publicado em 1972)

Foucault, M. (1995b). Sobre a história da sexualidade. In R. Machado (Ed., trans.), Microfisica do poder (pp. 243-276). Rio de Janeiro: Graal. (Trabalho original publicado em 1979)

Foucault, M. (2003). Le pouvoir psychiatrique. Cours au Collège de France. 1973-1974. Paris: Gallimard/Seuil.

Gadet, F., \& Hak, T. (Eds.). (1997). Por uma análise automática do discurso: Uma introdução à obra de Michel Pêcheux (B. S. Mariani et al., trans.). Campinas: Editora da Unicamp.

Martínez-Hernáez, A., Masana, L., \& Digiacomo, S. M. (Eds.) (2013). Evidencia y narrativas en la atención sanitária.
Una perspectiva antropológica. Tarragona: Publicacions URV-RedeUnida. Recuperado de http://www.redeunida.org. $\mathrm{br} /$ editora/biblioteca-digital/evidencias-y-narrativas-en-laatencion-sanitaria-pdf

Monceau, G. (2008). Implicação, sobreimplicação e implicação profissional. Fractal Revista de Psicologia, 20(1), 19-26.

Passos, I. C F. (2009a). Loucura e sociedade. Discursos, práticas e significações sociais. Belo Horizonte: Argvmentvm.

Passos, I. C F. (Ed.) (2009b). Poder, normalização e violência. Incursões foucaultianas para a atualidade. Belo Horizonte: Autêntica.

Rodrigues, H. C. (2009). Sobre arquivos e tumbas: Uma análise da expressão "documento como monumento". In E. Lourenço, M.C. Guedes, \& R. H. F. Campos (Eds.), Patrimônio cultural, museus, psicologia e educação: Diálogos (Coleção Encontros Anuais Helena Antipoff). Belo Horizonte: PUC Minas.

Searle, J-R. (1981). Actos de fala. Coimbra: Almedina. (Trabalho original publicado em 1969) 